\title{
Discharge planning: Narrated by nursing staff in primary healthcare and their concerns about using video conferencing in the planning session - An interview study
}

\author{
Malin Hofflander ${ }^{1}$, Lina Nilsson ${ }^{1}$, Sara Eriksén ${ }^{2}$, Christel Borg $^{1}$ \\ 1. School of Health Science, Blekinge Institute of Technology, Sweden. 2. School of Computing, Blekinge Institute of \\ Technology, Sweden. \\ Correspondence: Malin Hofflander. Address: School of Health Science, Blekinge Institute of Technology, SE-371 79 \\ Karlskrona, Sweden. Telephone: 46(0)-456-731-155. E-mail: malin.hofflander@bth.se. \\ Received: May 28, 2012 \\ DOI : $10.5430 /$ jnep.v3n1p88 \\ Accepted: J une 27, 2012 \\ URL: http://dx.doi.org/10.5430/jnep.v3n1p88
}

\section{Abstract}

Background/Objective: This paper sets out to describe experience-based reflections on discharge planning as narrated by nursing staff in primary healthcare, along with their concerns about how the introduction of video conferencing might influence the discharge planning situation.

Methods: Interviews were conducted with nursing staff working at a primary healthcare centre in South East Sweden. Each interview took place was conducted on a one-to-one basis in dialogue form, using open questions and supported by an interview guide. It was then analysed using a phenomenological hermeneutic method. Participants were eligible for the study if they had given their informed consent and if they worked with discharge planning and home-based healthcare provision. In total, 10 of the 30 persons working at the primary healthcare centre participated in the study.

Results: It was found that nursing staff in primary healthcare regarded the planning session as stressful, time-consuming and characterised by a lack of respect between nursing staff at the hospital and nursing staff in primary healthcare. They also described uncertainty and hesitation about using video conferences where patients might probably be the losers and nursing staff the winners.

Conclusions: It is suggested that there is a need for improvement in communication and understanding between nursing staff at the hospital and nursing staff in primary healthcare in order to develop discharge planning. There is also a need for the nursing staff in primary healthcare to obtain more information about how Information Technology (IT) solutions could support their work and help them to find ways to collaborate.

\section{key words}

Discharge planning, Healthcare, Information technology (IT), Nursing staff, Phenomenological hermeneutical, Video conference

\section{I ntroduction}

Comprehensive discharge planning in Sweden is governed by rules ${ }^{[1]}$ and should include participants from the hospital, primary healthcare and the municipality together with the patient and, if possible, the next of kin ${ }^{[1,2]}$. However, earlier 
research ${ }^{[3]}$ and experience have shown that because of time constraints, many of the discharge sessions that ought to be carried out do not take place at all and instead phone calls are made between the different stakeholders ${ }^{[4]}$. In this context, the discharge planning is seen as an opportunity for the stakeholders involved to meet at the hospital - using a common arena for discussions and sharing information - to plan the further care for the patient ${ }^{[4]}$. This is a way to reach agreement on which unit is responsible for each initiative in order to make further care safe and suitable for the patient after discharge ${ }^{[5]}$. The discharge planning should also result in a written plan approved by the patient and the stakeholders ${ }^{[4,5]}$. Nursing staff at Swedish hospitals state in some qualitative studies ${ }^{[6,7]}$ also reported in a case study from the UK ${ }^{[8]}$ that carefully completed discharge planning are complicated to run due to differences in perception and shortcomings in the flow of patient information between the professionals involved. It also seems to be unclear when nursing staff in primary healthcare assume full responsibility for the patient's further care after discharge ${ }^{[6]}$. This is related to uncertainty and inequality between the responsibilities of the different parties in the discharge planning process ${ }^{[9-11]}$, and it has been shown in studies that this leads to frustration and bad feelings about the task ${ }^{[12,13]}$. Length of stay in hospital and the readmission rate are also linked to defective discharge planning ${ }^{[14]}$. However, several studies have examined factors required for discharge planning to succeed: a guarantee by nursing staff that they will participate, participation by the patient and sound appraisal of the patient's need for further care after leaving hospital ${ }^{[1,6,9,15]}$. The ability to ensure the transfer of information between different stakeholders in an IT-based system is seen as a success factor ${ }^{[11]}$. Furthermore, a systematic review study shows that a structured discharge plan tailored to the individual will lead to an increase in patient satisfaction as well as participation by the patient ${ }^{[14]}$. On the other hand, in two Swedish interview studies, patients describe discharge planning as an occasion without the opportunity to discuss in private. They also recount experiences of not being listened to, not being able to understand what is going on, not being aware of how decisions are made and not knowing what is going to happen after their discharge from hospital ${ }^{[6,16]}$. In fact, the patient, who is the main figure in the discharge planning process, is not being allowed to participate in the planning session. In one interview study, it is suggested that methods should be implemented for setting goals and identifying patients' needs in order to facilitate and increase patient participation in discharge planning ${ }^{[17]}$. A review study that asks if we are delivering best practice states that discharge planning, with interventions to address interdisciplinary communication and combined with post-discharge support, significantly improve health outcomes ${ }^{[18]}$. A meta-analysis also reports the same based on statements by older patients with congestive heart failure ${ }^{[19]}$. Wong et al. found in a qualitative study from Hong Kong that barriers to effective discharge planning were lack of standardised, hospital-wide discharge planning and a policy-driven approach. A further potential barrier was lack of communication and co-ordination among different stakeholders and patients ${ }^{[20]}$. Difficulties in discharge planning have been an area of concern for more than 20 years and the challenge of improving the planning session and addressing communication between professions is described in a comparative study based on data from Sweden and the UK ${ }^{[3]}$. However, it would seem that problems related to communication among participants in the traditional discharge planning process are examined in many ways ${ }^{[18-20]}$. Person-centred nursing, where the nursing staff establish relationships with the patient, and a more modern way of communicating are perhaps needed if progress is to be made in this area ${ }^{[21]}$. It might also be important for the nursing staff to see the discharge planning from the patient's point of view and be aware of the patient's future needs. By doing this we can, as described by Rogers, see the patient as a wholeness, where the human being is regarded as a unified whole that is more than and different from the sum of the parts ${ }^{[22]}$. A Swedish study describes the need for further innovative work, especially concerning the implementation of IT solutions to support and enhance discharge planning, where IT solutions are seen as untapped potential for improvement ${ }^{[23]}$. According to the literature, the ability of the manager to understand and lead organisations in processes of change could also be an important factor when introducing new ways of working and new IT solutions ${ }^{\text {[24, 25]. }}$.

There is a whole host of issues being raised concerning discharge planning, where the situation is complex and includes many different parts if it is to work. The aim of this study was to highlight the experience of nursing staff in primary healthcare regarding discharge planning sessions and to pick up on their concerns regarding the use of video conferencing in the discharge planning session. 


\section{Methods}

\subsection{Study design}

A qualitative interview study was carried out with nursing staff working in a primary healthcare centre in South East Sweden. The interviews focused on the experience of nursing staff in primary healthcare in planning for the further care of patients at home after leaving hospital; communication during the planning sessions between nursing staff working in primary healthcare and nursing staff working at the hospital and, finally, their concerns about introducing an IT solution, consisting of a video conference system, into the discharge planning session. Participants were eligible for the study if they had given their informed consent and if they worked with providing healthcare to patients in their homes and were district nurses, occupational therapists or physiotherapists.

\subsection{Data collection}

Interviews were conducted during working hours on a one-to-one basis and took place in a small conference room at the healthcare centre. Each interview lasted 30-50 minutes and took the form of a dialogue. The questions were open, with a focus on the main areas covered by the study and with the support of an interview guide. The two main questions were: Could you tell me about your experience of discharge planning sessions? Could you tell me about your concerns regarding the use of video conferencing in the discharge planning session? The supporting questions were: Can you go into more detail? Can you tell me more about this? Can you elaborate? The supporting questions were used to help the informants gain a grasp of their narrations. The interviews were then transcribed verbatim, and an understanding of the text was gained from an initial reading. To gain an overall understanding, the text was read repeatedly by the researcher. The minimum number of participants for our study was 10, which is one-third of the 30 persons working with discharge planning and who have the primary healthcare centre as their place of work. The number should also include at least one person from each of the professional groups working at the primary healthcare centre with discharge planning, i.e. a district nurse, an occupational therapist and a physiotherapist. District nurses accounted for the largest number of persons involved in discharge planning at the centre. Of the 30 employees in question, 19 were district nurses, five were occupational therapists and six were physiotherapists. The nursing staff declared their interest in participating a few days after being informed about the study and the specified number of representatives from the different professional groups was achieved. In total, seven district nurses, two occupational therapists and one physiotherapist participated in the study. The participants had been working in their profession for 3-15 years. They had all worked for more than three years at the care centre. The age range of the participants was 30-65 years. All of them were in the near future about to participate in a distance-based discharge planning session, where a video conference system would be used in the planning sessions. All participants gave their informed consent before participating in the study.

\subsection{Data analysis}

A qualitative, phenomenological hermeneutical method for interpreting interview texts was used in this study. The method has been elaborated on by Lindseth \& Norberg ${ }^{[26]}$, who are inspired by the theory of interpretation presented by Paul Ricoer ${ }^{[27]}$. The analysis process includes three phases: naïve reading, structural analysis and comprehensive understanding. The starting point of the analysis is the experiences related by the respondents in the interviews. In the naïve reading, the researcher confines the meaning to the whole of the narration in the text, linked to its context. To gain an overall understanding, the text is read many times by the researcher. The structural analysis of the text validates or invalidates the researcher's overall understanding of the text as acquired in the naïve reading. The structure of the text is in focus in this phase, while units of meaning in the text are being sought that explain what the text is saying along with the meaning of the lived experience. The third phase, comprehensive understanding, is the researcher's final interpretation of the text, and is a movement between interpretation and understanding of the lived experience, based on pre-understanding, literature, the naïve reading and the structural analysis. 


\subsection{Ethical considerations}

To guarantee anonymity, no names, neither real nor fictitious, will be revealed in this article. The participants gave their informed consent before the study was made. The authors have been in contact by phone with the Ethics Committee in South East Sweden (Etikprövningskommittén i Sydost) about the study to observe the ethical aspects. Permission for the study was granted by the Committee and no further application was needed.

\section{Results}

\subsection{Naïve reading}

The naïve understanding of this paper presents unified material in which all respondents (irrespective of their profession, age and work experience) narrated their professional experience of discharge planning. At the same time, the respondents talked about their experience of lack of consideration and knowledge on the part of the hospital nursing staff involved in discharge planning. The respondents agreed that discharge planning has received an unwarranted stamp of being a trivial matter due to the many uncertainties and the schism within the context. The respondents also agreed that IT always improves the status of an activity. However, all the respondents felt unsure about how IT would facilitate understanding and communication in the discharge planning process due to the respondents' uncertainty regarding implementation and use of this new working tool. Despite insufficient knowledge about distance-based discharge planning on the part of the respondents they all agreed that in the main, staff would be supported by it while the patient would not benefit as much if discharge planning were to be done on a distance basis using video conferencing.

\subsection{Structural analysis}

The structural analysis resulted in two themes, each with four sub-themes, which are presented in Table 1 . The results are presented and exemplified with quotations. The number following each quotation denotes the interview.

Table 1. Themes and sub-themes identified through structural analysis of the gathered data

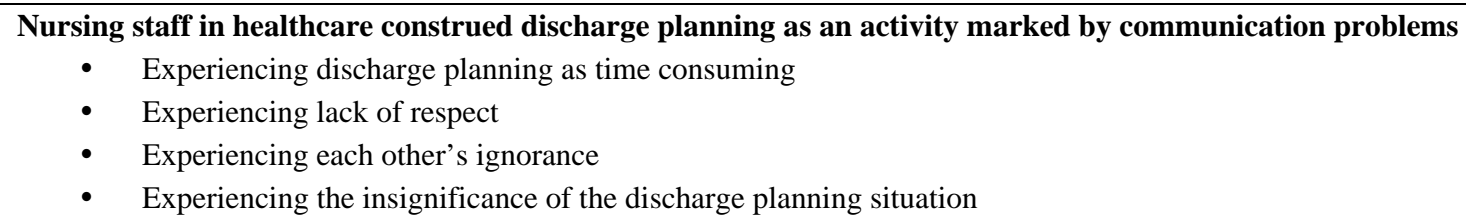

Feelings were ambiguous about video conferencing and discharge planning

- Experiencing uncertainty and indifference about using a video conference system in the planning session

- Expectations that the professionals will be the winners if a video conference system is used in planning sessions

- $\quad$ Expectations that the patient will be the loser if a video conference system is used in planning sessions

- Hopes that IT will enhance discharge planning

\subsection{Nursing staff in healthcare construed discharge planning as an activity marked by communication problems}

The respondents gave the impression that discharge planning represented lived experience of lack of communication, respect and knowledge. As a result, discharge planning has become an insignificant activity.

\subsubsection{Experiencing discharge planning as time consuming}

Discharge planning is perceived as an activity that takes up too much of the respondents' time. Several of the respondents noted that discharge planning is time-consuming or, as one of them said: “A time thief” (Respondent 4). 
All respondents indicated, in one way or another, that discharge planning was stressful:

"I think it can sometimes feel very chaotic inside the hospital, that the nurse can only ... they can only take part for, like, five minutes (...) I get so frustrated!” (Respondent 1)

The hospital nursing staff decide when it is time to prepare a discharge plan for a patient. According to the respondents, they are also the ones who book a time for the discharge planning session. Our respondents felt that discharge planning is arranged at very short notice, and this makes it difficult to fit it into the schedule of the nursing staff in primary healthcare. It is constantly "hurry, hurry!” (Respondent 2)

The respondents thought that the short planning horizon could be attributed to the fact that the nursing staff at the hospital want to send patients home as quickly as possible when they are considered healthy enough to be discharged. The respondents implied that there is an inherent problem in the discharge planning activity and the time it takes.

\subsubsection{Experiencing lack of respect}

The respondents experienced a lack of respect between the nursing staff at the hospital and the nursing staff in primary healthcare. According to the respondents, nursing staff at the hospital not only show a lack of respect for the time aspect but also a lack of understanding of the daily routine at the primary healthcare centre:

"They have no understanding of what we do, and we forget what it's like at the hospital. It's a delimited world of its own, isn't it? ... Yes, (...) you don't have any understanding whatsoever of the other world” (Respondent 6).

When the nursing staff at the hospital are unprepared for discharge planning, the respondents felt irritated and interpreted this behaviour as an outcome of non-involvement and a lack of interest by the hospital nursing staff. The respondents felt that a lack of interest is also shown towards the patients.

\subsubsection{Experiencing each other's ignorance}

According to the respondents, a kind of ignorance has emerged, both of each other's professions and of what a discharge plan should include. This ignorance creates misunderstandings and uncertainty. The interviews showed explicitly that nursing staff in healthcare are unsure of what a discharge planning session should include. Sometimes there can be an inventory error in discharge planning and the patient’s needs are not listed at the hospital.

"It is vital that you know how to perform discharge planning (...) and that is not always how it is ... Now, you don't think. You just do it” (Respondent 8).

This ignorance is also evident among nursing staff in healthcare and in hospitals, who have minimal knowledge of each other's professions and roles in a discharge planning situation. Furthermore, the respondents indicated that in a discharge planning situation, the nursing staff at the hospital know very little about the patient. The respondents commented that the ignorance displayed in a discharge planning situation "diminishes" the patient (Respondent 8). According to the respondents, the ignorance of each other's profession results in misconceptions about who should do what in a discharge planning situation and about who has the responsibility for a discharged patient.

\subsubsection{Experiencing the insignificance of a discharge planning situation}

The nursing staff in healthcare found discharge planning to be insignificant due to a lack of knowledge and respect and also due to different views of the time associated with discharge planning. The respondents maintained that discharge planning becomes 'inaccessible' and thus negligible for the staff involved, both in primary healthcare and at hospitals. "It could be an optimal situation but now we don't get all the pieces (...) it is meaningless ...” (Respondent 2). "The experience of meaninglessness results in a 'diffuse' discharge planning situation” (Respondent 3). Hence, the respondents found it meaningless to go to a discharge planning session. They would rather stay at the primary healthcare centre and not 
participate at all or send someone else to the session. According to Respondent 1 , the information received from the discharge planning session is not always explicit. The respondent explained that sometimes it is necessary to translate the information into something more significant.

Ambiguities and the sense of insignificance of a discharge planning session result in uncertainty when the patient comes home after a hospital stay. It all ends with no one knowing what the patient really needs and therefore a second planning meeting is often necessary. According to the respondents, this increases the sense of meaninglessness of discharge planning at the hospital.

\subsection{Feelings were ambiguous about video conferencing and discharge planning}

The respondents related lived experiences of discharge planning to the forthcoming change in work practice in which IT would be implemented in this process. The respondents were not convinced that this would work out.

\subsubsection{Experiencing uncertainty and indifference about using a video conference system in the planning session}

The respondents felt that there have been very few meetings about the implementation of a video conference system in the planning session at the primary healthcare centre. There were no meetings at a later date for those who did not have the time to attend the initial meeting. Due to lack of interest and lack of time, the respondents who had missed the initial meeting had not bothered to obtain information about the ongoing implementation process. Several respondents said they would like to try out the new way of working with planning sessions to "Get it done and then we'll know" (Respondent 1), while others expressed more reluctance to the idea of an IT solution: "Why do we need to change everything?" (Respondent 4).

\subsubsection{Expectations that the professionals will be the winners if a video conference system is used in planning sessions}

Although they voiced ambiguous feelings and lack of commitment concerning distance-based discharge planning, the respondents were of the opinion that they would actually be the winners if/when a new way of discharge planning is implemented. Several respondents indicated that the greatest benefit of a video conference system was the time they would save. Respondents also agreed that it was primarily the time it took to drive to the hospital and back that would be saved with distance-based discharge planning. Nevertheless, some respondents noted that the time spent driving together in a car together to and from the hospital was a great opportunity for the staff from primary healthcare and the municipality to discuss the patient and the discharge planning. Several respondents emphasised the problems that would occur when nursing staff in healthcare and nursing staff at the hospital do not meet in person when/if distance-based discharge planning takes place. The respondents did not want to comment on whether there would be an overall gain or loss in that question in that area. However, several respondents pointed out that the staff involved in the planning are bound to communicate if the discharge planning takes place at a distance, since they must all be in place at a certain time to be able to attend the discharge planning session.

\subsubsection{Expectations that the patient would be the loser if a video conference system is used in planning sessions}

The respondents were convinced that the patient would be the loser if video conferences were used in planning sessions. According to Respondent 7, the new discharge planning process has "lost sight of the patient and the patients are precisely the ones who should come in (...) in this new type of discharge planning”. From a patient perspective, the human touch in the activity would be lost. The respondents expressed concern that:

"Without a face-to-face meeting it will be different (...) and for the patient, it is the patient who should be the centre of our interest... I am very doubtful about it. What is going to happen now...?” (Respondent 7) 


\subsubsection{Hopes that IT will enhance discharge planning}

Many of the respondents were hopeful that IT would provide added status to discharge planning. Respondent 4 pointed out that IT would assign higher status to discharge planning since it is associated with "manliness" and "people do look respectful as soon as you start talking about megabytes and gigabytes, hard disks and processors, don’t they...”

\subsection{Comprehensive understanding}

The participants' accounts point out that communication within the context, both in definitions of concepts and within the group, is rather poor. The experiences of this communication are not seen to be important and time is not allocated to make improvements. The participants' concerns about using video conferencing in the discharge planning session were ambiguous and illustrated their apprehension that nursing staff would be the winners and patients would be the losers if an IT solution were implemented.

\section{Discussion}

The aim of this study was primarily to highlight the experience of nursing staff in primary healthcare regarding discharge planning. The results of our study indicate that discharge planning sessions as they are carried out at present are perceived as complicated and time-consuming. This seems to be a persistent problem. According to a number of earlier studies, nursing staff state that discharge planning sessions are complicated due to differences in perception and shortcomings in the flow of patient information between the professionals involved ${ }^{[6-8]}$. It can be seen that the nursing staff in our study underestimate their need to participate to make discharge planning really work. Even if they know how important the planning session is for further care at home, they do not really see the benefit of their own participation in relation to the time they spend on it. Our study also shows that the respondents experience a lack of respect between them and the nursing staff at the hospital. Spence Laschinger's ${ }^{[28]}$ description is similar, and she points out that a positive organisational environment increases the nurses' perceptions of respect, resulting in positive outcomes for both the nurse and the organisation. This lack of respect could perhaps be connected to ignorance of each other's professions, about the stakeholders involved and about what a discharge plan should include. Both Robinson \& Street ${ }^{[11]}$ and Nazarko ${ }^{[13]}$ describe perceived inequality between different parties' responsibilities within the discharge planning activity and its outcome. This lack of power to negotiate and change an unsatisfactory situation seems to be confirmed by our study. Consequently, none of the respondents expressed any intention of taking steps to reconstruct their own role and gain better control of their own knowledge within the discharge planning process, such as developing and using some kind of checklist to gain a better feeling and overview of what a planning session should include. Nor did they seem to explicitly require given rules from the county council or mention ongoing discussions with the nursing staff at the hospital about what would be proper content for a discharge planning session. Such requirements and discussions could conceivably be part of making discharge planning a less frustrating and more co-constructive, effective and sustainable activity. Our study implies a lack of communication within discharge planning and that there may be insufficient time to improve it. Even if there is a lack of time, there is a need for the nursing staff to prioritise communication. Making communication work ought to be an extremely important issue for the nursing staff who work with discharge planning. Williams \& Gossett ${ }^{\text {[29] }}$ argue that communication between patients and nursing staff is a key component of effective healthcare and lays the foundation for a safe and secure nursing environment. McCormack ${ }^{[21]}$ also underlines the importance of functioning communication and being patient-centred. With this in mind, we argue that it is important for nursing staff who take part in discharge planning to communicate and cultivate interorganisational spaces for sharing professional knowledge, experiences, expectations and concerns in order to sort out and elaborate on new working routines for discharge planning. If implementation of new information and communication technologies can be deliberately attuned to highlighting and providing workable solutions for knowledge-sharing and ongoing negotiations of roles and responsibilities - not only within and between different nursing staff but also including patients and their next of kin as active stakeholders - then new tools such as video conferencing in the discharge planning process might have truly revolutionary potential. 
The aim of this study was also to pick up the concerns among nursing staff in primary healthcare about using video conferencing in the discharge planning session. The respondents consider the information they have received about the video conference system to be inadequate and poorly managed. This is confirmed by Holmberg \& Tyrstrup ${ }^{\text {[24] }}$, who state that sufficient time and space for discussions is needed when a new way of working is to be successfully implemented at a workplace. It must begin with a successful communication process, including iterative and easy-to-understand information. Furthermore, the respondents all voice concerns that the patient will be left outside the interaction and communication, when video conferencing comes into the picture. However, this study declares that the patient already has difficulties in today's discharge planning due to the dysfunctional interaction between different stakeholders. Efraimsson et al. ${ }^{[30]}$ state that discharge planning in its present form does not enhance the possibility for the patients to express their personal wishes in a dignified manner. It also interferes with a caring perspective that protects patients' integrity. As Rogers ${ }^{[22]}$ states, seeing the patient as a wholeness is not possible when the patient's perspective is being overshadowed by dysfunctional interaction. Somewhat surprisingly, the respondents all shared the opinion that they would be the winners and the patients' would be the losers when a video conference system is implemented. None of the respondents reflected on the fact that patients are already not actively involved in the planning session, which makes it seem like an activity that only involves the professionals. The respondents' expectation was that video conferences could save time and improve interaction in discharge planning. They regard the use of technology as positive, while Aanesen et al. ${ }^{[31]}$ explain to some extent the opposite way in their study that even if appropriate technology is available, there is general resistance to substituting 'warm' hands with 'cold' technology in the healthcare sector. However, Berg ${ }^{[32]}$ notes that a technical solution will not always be the best solution in a heterogeneous context because of the complexity of the context where the patient, not the technology, should be the focus of communication in a caring context. The results of our study show that even if there might be a poor flow of information about the technology that is being implemented, the respondents believe they will gain from the introduction of video conferences into the discharge planning sessions. With a distance-based solution, the system and the control within the activity must change in order to ensure everyone is equally involved. In an earlier study, Sawyer ${ }^{[33]}$ argues that IT solutions may strengthen the interaction between different stakeholders, as IT elucidates the need to work out rules and norms in communication. Sawyer ${ }^{[33]}$ also points out that technical solutions often reveal conflicts and divided opinions. It would seem that rules and norms are a problem that needs to be sorted out between the nursing staff in primary healthcare and the nursing staff at the hospital. Implementing a new discharge planning procedure by using video conferencing will not solve the communication problems, which seem to be quite severe. When implementing new working routines, Holmberg \& Tyrstrup ${ }^{[24]}$, state that one of the most distinctive characteristics of everyday leadership is the need to be event-driven. This, as well as the ability of the leader to understand and lead organisations in challenging processes of change, is seen to be an important success factor ${ }^{[24,25]}$. Accordingly, it might be important for the nursing staff in primary healthcare to gain the active support of their manager in order to be able to introduce discharge planning with a video conference system as a common routine. The ability of professionals to discuss and influence new ways of working can be seen as an underestimated success factor when the focus is on improvement. In combination with understanding why decisions are made to change the work being done, this might also be seen as important.

\section{Methodological considerations}

The phenomenological hermeneutic method ${ }^{[26]}$ used in this study was a suitable method to illustrate the meaning of nursing staff working with lived experiences in healthcare. A deeper understanding was gained as they expressed their thoughts, feelings and concerns about discharge planning, as well as their concerns and expectations about introducing video conferencing in the discharge planning session. The participants recruited for our study were all voluntary and all of them were currently taking part in discharge planning and were in the near future going to participate in discharge planning where a video conference system would be used in the planning sessions. It must be taken into account that the participants may have been persons who were more able to express themselves and were more interested in making their voice heard, than the ones who chose not to participate. The participants are addressed as nursing staff throughout our study, a group in which occupational therapists and physiotherapists are not normally included. Nevertheless, in this study we choose to 
address everyone as nursing staff as there were no differences in the respondents' answers due to their professional affiliation.

The researchers' perspectives as nurses, teachers and managers should also be considered an influencing factor in the process. To be aware of the pre-understanding and being able to handle this is important in hermeneutic research ${ }^{\text {[34] }}$. However, a qualitative research interview can be seen as a way of acquiring descriptions from the respondents' life world, followed by an interpretation of the phenomenon and the meaning of the narrations ${ }^{[26]}$. In qualitative research, trustworthiness, described by both Graneheim \& Lundman ${ }^{[35]}$ and Lincoln \& Guba ${ }^{[36]}$, is also highlighted as being important to achieve. This could be supported in our study by strict structural analysis, similarities with the results of earlier studies and discussing our results with other colleagues.

\section{Conclusion}

Planning for patients' further care after discharge from hospital is an activity that is regulated in health and welfare legislation. Despite this, our study indicates that this activity is not working out as intended and it is not taken seriously by the nursing staff in primary healthcare and at the hospital. Interpersonal communication, combined with the ability to focus on the patient, might be a success factor where video conferencing would seem to have the potential to enhance the discharge planning process. However, there might be difficulties in the process if the nursing staff involved do not understand why a new working routine is to be implemented, especially when it seems that the staff have difficulty seeing the importance of discharge planning generally. When new working tools are to be implemented, there is need for accurate preparatory work, both by the nursing staff involved and their managers. Our study implies that there is a need to support both nursing staff in primary healthcare and nursing staff at the hospital to help them understand the importance of collaboration around the patient and the patient's needs in the discharge planning process, and how new solutions, such as video conferencing, might be used in this context.

\section{Further research}

Preliminary results from the implementation of a video conferencing system in discharge planning indicate that by redesigning work practices in combination with implementing new IT solutions, discharge planning could be made more accessible and transparent for patients, next of kin and professionals. However, the results indicate a need for further studies to obtain a broader understanding of the experiences of the nursing staff in primary healthcare, the patients, the next of kin and the nursing staff at the hospital, and to explore how these experiences can be brought to bear on design-in-use of supportive IT solutions for enhancing discharge planning. At the same time, it may be important to investigate the support of managers and organisations when new working routines are to be implemented in the future.

\section{Acknowledgements and funding}

The authors would like to thank all participants for their willingness to share their experiences.

This study was supported in part by Blekinge Research Council, which is run jointly by Blekinge County Council and Blekinge Institute of Technology.

\section{Competing interests}

The authors declare that they have no competing interests

\section{References}

[1] The National Board of Health and Welfare in Sweden: Social interaction at entry and discharge of patients in closed care, AFFAIRS. 2005; 27. 
[2] Law of Health and Medical Services in Sweden. 1982; 763.

[3] Lundh U, Williams S. The challenges of improving discharge planning in Sweden and the UK: different but the same. Journal of Clinical Nursing. 1997; 6 (6): 435-442. PMid:9526349 http://dx.doi.org/10.1111/j.1365-2702.1997.tb00340.x

[4] Larsson K. Call for Discharge planning - How it went on? The National Board of Health and Welfare in Sweden, 2007, Article nr. 2008; 126: 19.

[5] The National Board of Health and Welfare in Sweden: Rules about handling information and records in medical care, AFFAIRS. 2008; 14.

[6] Norberg H, Sjögren Holm L. Routines and transmission of information in discharge-planning session: experiences and present situation. R\&D report; Carelink, Stockholm. 2006.

[7] Gurner U, Wånell S. E. Pre-treated...and then? The older patient discharge from hospital. Summaries of two sub studies within follow-up by the Development plan of County Council of Stockholm. Reports/Foundation Centre of Elder in County Council of Stockholm, Stockholm. 1998.

[8] Atwal A. Nurses' perceptions of discharge planning in acute health care: a case study in one British teaching hospital. Journal of Advanced Nursing. 2002; 39 (5): 450-458. PMid:12175354 http://dx.doi.org/10.1046/j.1365-2648.2002.02310.x

[9] Efraimsson, E. Discharge-planning session; a study of the institutional conversation between older women, next of kin and carer. PhD Thesis. University of Umeå, Department of Nursing, 2005.

[10] Guadagnoli E, Ward P. Patient participation in decision-making. Social Science Medicine. 1998; 47 (3): 329-339. http://dx.doi.org/10.1016/S0277-9536(98)00059-8

[11] Robinson A, Street A. Improving networks between acute care nurses and an aged care assessment team. Journal of Clinical Nursing. 2004; 13 (4): 486-496. PMid:15086635 http://dx.doi.org/10.1046/j.1365-2702.2003.00863.x

[12] Hegney D, McCarthy A, de la Rue M B, Fahey P, Gorman D, Martin-McDonald K, Pretty G, Sundin-Huard D. Discharge planning from the acute sector for people over the age of 65. Collegian. 2002; 9 (3): 15-21. http://dx.doi.org/10.1016/S1322-7696(08)60420-5

[13] Nazarko L. Improving discharge: the role of the discharge co-ordinator. Nursing Standard. 1998; 12 (49): $35-37$.

[14] Shepperd S, McClaran J, Phillips C O, Lannin N. A, Clemson L M, McCluskey A, et al. Discharge planning from hospital to home. Cochrane Database Syst Rev. 1: 2010. CD000313. PMid:20091507

[15] LeClerc C M, Wells D L, Craig D, Wilson J L. Falling short of the mark: tales of life after hospital discharge. Clinical Nursing Research. 2002; 11 (3): 242-263. PMid:12180639 http://dx.doi.org/10.1177/10573802011003002

[16] Littorin C. Coordinated discharge-planning - for whom? R\&D unit for elderly and disabled by County of Halland, Halmstad. 2001; R\&D report. 2001; 1.

[17] Almborg A H, Ulander K, Thulin A, Berg S. Patients' perceptions of their participation in discharge planning after acute stroke. Journal of Clinical Nursing. 2009; 18 (2): 199-209. PMid:18702620 http://dx.doi.org/10.1111/j.1365-2702.2008.02321.x

[18] Bauer M, Fitzgerald L, Haesler E, Manfrin M. Hospital discharge planning for frail older people and their family. Are we delivering best practice? A review of the evidence. Journal of Clinical Nursing. 2009; 18 (18): 2539-2546. PMid:19374695 http://dx.doi.org/10.1111/j.1365-2702.2008.02685.x

[19] Phillips C O, Wright S M, Kern D E, Singa R M, Shepperd S, Rubin H R. Comprehensive discharge planning with postdischarge support for older patients with congestive heart failure: a meta-analysis. Journal of the American Medical Association. 2004 ; 291 (11): 1358-1367. PMid:15026403 http://dx.doi.org/10.1001/jama.291.11.1358

[20] Wong E L Y, Yam C H K, Cheung A W L, Leung M C M, Chan F W K, Wong F Y Y, Yeoh E K. Barriers to effective discharge planning: a qualitative study investigating the perspectives of frontline healthcare professionals. Bmc Health Serv Res. $2011 ; 11$. PMid:21241473

[21] McCormack B. A conceptual framework for person-centred practice with older people. International Journal of Nursing Practice. 2003; 9 (3): 202-209. PMid:12801252 http://dx.doi.org/10.1046/j.1440-172X.2003.00423.x

[22] Rogers, M. E. An introduction to the theoretical basis of nursing Philadelphia, F. A. Davis Co.1970.

[23] Petersson H. Inventory of patients which discharge from hospital and the planning session in connection with the discharge. The National Board of Helath and Welfare, Stockholm, 2007.

[24] Holmberg I, Tyrstrup M. Well then - What now? An everyday approach to managerial leadership. Leadership. 2010 ; 6(4): $353-372$. http://dx.doi.org/10.1177/1742715010379306

[25] Mintzberg H. Rounding out the manager's job. Sloan Management Review. 1994; 36 (1): 11-26.

[26] Lindseth A, Norberg A. A phenomenological hermeneutical method for researching lived experience. Scandinavian Journal of Caring Sciences. 2004; 18 (2): 145-153. PMid:15147477 http://dx.doi.org/10.1111/j.1471-6712.2004.00258.x

[27] Ricoeur, P. Interpretation Theory: Discourse and the Surplus of Meaning. Texas Christian University Press, 1976. 
[28] Spence Laschinger H K. Hospital Nurses' Perceptions of Respect and Organizational Justice. Journal of Nursing Administration. 2004; 34 (7-8): 354-364. http://dx.doi.org/10.1097/00005110-200407000-00009

[29] Williams C A, Gossett M T. Nursing Communication: Advocacy for the Patient or Physician? Clinical Nursing Research. 2001 ; 10 (3): 332-340. PMid:11881946 http://dx.doi.org/10.1177/10547730122158969

[30] Efraimsson E, Sandman P-O, Hydén L-C, Holritz Rasmussen B. How to get one's voice heard: the problems of the discharge planning conference. Journal of Advanced Nursing. 2006; 53 (6): 646-655. PMid:16553673 http://dx.doi.org/10.1111/j.1365-2648.2006.03771.x

[31] Aanesen M, Lotherington A T, Olsen F. Smarter elder care? A cost-effectiveness analysis of implementing technology in elder care. Health Informatics Journal. 2011; 17 (3): 161-172. PMid:21937460 http://dx.doi.org/10.1177/1460458211409716

[32] Berg M. Patient care information systems and health care work: a sociotechnical approach. International Journal of Medical Informatics. 1999; 55 (2): 87-101. http://dx.doi.org/10.1016/S1386-5056(99)00011-8

[33] Sawyer S. Social Informatics: Overview, Principles and Opportunities. Bulletin of the American Society for Information Science \& Technology. 2005; 31 (5): 9-12.

[34] Polit D F, Beck C T. Essentials Of Nursing Research: Methods, Appraisal, And Utilization. Lippincott Williams \& Wilkins, 2006.

[35] Graneheim U H, Lundman B. Qualitative content analysis in nursing research: concepts, procedures and measures to achieve trustworthiness. Nurse Educ Today. 2004; 24 (2): 105-112. PMid:14769454 http://dx.doi.org/10.1016/j.nedt.2003.10.001

[36] Lincoln Y S, Guba E G. Naturalistic Inquiry. Newbury Park: Sage Publications, 1985. 